\title{
A PROPÓSITO DE LAS CATEGORÍAS GRAMATICALES DE IGNACIO BOSQUE. ¿UNA NUEVA PERSPECTIVA SOBRE SUS RELACIONES Y DIFERENCIAS?
}

\author{
Olga Ivanova \\ Universidad de Salamanca
}

\section{Resumen}

Como unidades básicas de la sintaxis de cualquier lengua, las categorías gramaticales constituyen un objeto de estudio habitual en la gramática española. Sin embargo, el funcionamiento sintáctico de algunas unidades léxicas suscita serios problemas a la hora de adscribirlas de forma definitiva a una determinada clase. El presente trabajo ofrece una visión panorámica de cómo pueden ser tratados los problemas de clasificación de algunos elementos léxicos a partir de la segunda edición del manual Las categorías gramaticales: relaciones y diferencias, de Ignacio Bosque. Recoge, a partir de esta edición revisada del gramático, los ejemplos más llamativos de los escollos con los que uno puede toparse en el análisis sintáctico de las partes de la oración tradicionalmente denominadas léxicas y funcionales.

Palabras clave: Categorías gramaticales, análisis sintáctico, clasificación, función gramatical.

\section{ON LAS CATEGORÍAS GRAMATICALES BY IGNACIO BOSQUE: A NEW PERSPECTIVE ON THEIR RELATIONS AND DIFFERENCES?}

\begin{abstract}
As basic units of the syntax of any language, grammatical categories have been consistently studied by Spanish grammarians. However, there exists some lexical units whose syntactic behaviour presents serious challenges when assigning them definitively to a particular class. The present work provides an overview of how to face the problem of classification of several lexical units from the second edition of the manual Las categorias gramaticales: relaciones y diferencias by Ignacio Bosque. It collects, from this revised edition, the most striking examples of the pitfalls that may be encountered in the syntactic analysis of the parts of the sentence traditionally called lexical and functional.

Keywords: Grammatical categories, syntactic analysis, classification, grammatical function.
\end{abstract}




\section{El complejo estudio de las CATEgorías gramaticales}

Las categorías gramaticales - estas unidades básicas de la estructura sintáctica de cualquier lengua, que habitualmente se clasifican en función de sus accidentia, o de propiedades y formas contextuales (Fernández Pérez, 1987: 77) — han sido objeto de estudio ordinario en la tradición lingüística. Debido a la centralización de la gramática grecolatina en las palabras y no en otras cuestiones gramaticales (Piera, 2009: 27), la clasificación de diferentes partes de la oración data desde hace varios milenios y, curiosamente, llega hasta nuestros días en estado casi invariable en comparación con las primeras perspectivas (Satorre Grau, 2009: 129). No es de extrañar pues, como apunta Gutiérrez Ordóñez (1985: 77), que la distinción de las categorías gramaticales es un aspecto fundamental y básico de cualquier doctrina gramatical.

También llamadas clases de palabras, partes de la oración ${ }^{1}$ o categorías funcionales, dichos conjuntos de unidades, fundamentales en cualquier gramática, suscitan alguna que otra duda, o incluso problema, de corte formal y funcional para los teóricos de la lengua. Ante todo, el propio término «categoría gramatical» cuenta con más de una acepción dentro de la teoría sintáctica, pudiendo referirse a categorías léxicas y categorías funcionales, solo a alguna de ellas, o incluso a sus funciones (cf. Gutiérrez Ordóñez, 1985; Cervera, 2003). En la nueva edición del manual Las categorías gramaticales. Relaciones y diferencias (Síntesis, 2015), del que vamos a dar una visión panorámica en este trabajo, Ignacio Bosque define las categorías gramaticales como unidades básicas del análisis gramatical que equivalen a lo que tradicionalmente se ha referido como partes de la oración - a pesar de la ambigüedad de esta noción- y a las relaciones sintagmáticas, enmarcadas dentro de una multitud de otras tantas unidades del sistema sintáctico. Así, el gramático vuelve a abarcar uno de los problemas más básicos, pero no por ello menos complejo, el de la categorización de las palabras en español desde la perspectiva de su problemática, no solo de corte terminológico sino también de calado formal y funcional.

La precisión conceptual de la noción categoría gramatical no soluciona otro escollo serio de la teoría lingüística: ¿cuántas partes de la oración existen en español? La adscripción de las palabras a una serie de grupos preestablecidos no siempre y no necesariamente se produce a partir de factores homogéneos y dentro de unos límites no difusos (Satorre Grau, 2009: 130). Si bien no parece haber duda de que hermano es un sustantivo y feliz es un adjetivo, ¿qué hay de la palabra infeliz en oraciones como Tu hermano es un infeliz? Existe, por tanto, una cierta inconsistencia teórica sobre el número

\footnotetext{
1 Término calificado como «engañoso» por González Calvo (1992).
} 
de categorías gramaticales y los criterios de adscripción a dichas categorías, debido, fundamentalmente, como apunta Bosque, a la real dificultad de interpretar de forma inequívoca y unívoca algunos comportamientos gramaticales que ciertas partes de la oración pueden ofrecer en contextos sintácticos distintos. Ello incide, obviamente, en la manifestación práctica de la gramática en la mente humana: desde la psicolingüística, se ha afirmado que la habilidad de correctamente asignar palabras a una clase gramatical o, dicho de otra forma, categorizarlas, se encuentra ya presente en niños muy pequeños. Estos, aparentemente, ya pueden realizar una actividad de análisis formal a partir de ejemplos concretos del lenguaje que los rodea (Mariscal Altares, 2001) y almacenarlos con sus respectivas etiquetas gramaticales en su lexicón nativo (Baralo, 2001: 11). Lo curioso es que tal análisis formal, inherente a la habilidad lingüística humana desde que se establece con el aprendizaje de la lengua materna, no es siempre tan sistemático y regular como parece a primera vista. De hecho, la dificultad que la gramática puede plantear en la asignación de etiquetas a una clase gramatical u otra puede sorprender a muchos. El propio Ignacio Bosque apunta, en un trabajo anterior (2013: 237), que en la selección y el uso de unas categorías frente a otras el hablante nativo no duda de la forma en la que realizar las complejas operaciones sintácticas; pero ¿qué hay de la comprensión puramente teórica, gramatical de dichas complejas operaciones desde la teoría lingüística?

\section{Delimitando las categorías gramaticales, o las partes}

DE LA ORACIÓN

En la determinación de las categorías gramaticales han existido cuatro clasificaciones binarias de mayor alcance en la teoría lingüística, de las que el gramático madrileño ofrece un comentario crítico.

La primera de ellas opone categorías a partir de la propiedad flexiva, distinguiendo entre clases variables e invariables. Así, según este criterio de base morfológica, los sustantivos son una clase variable, dado que admiten marcas de flexión de género (gato/gata) y número (gatos) de forma sistemática. Sin embargo, existe una serie de problemas asociados a este criterio de clasificación de las partes de la oración. Además de implicar cuestiones de diferenciación semántica en pares como manzana/manzano, banca/banco o esposa/esposas (Piera, 2009: 36-37), acarrea unas destacables simplificaciones en relación con la aparición de marcas flexivas no sistemáticas, la distinción entre marcas flexivas por concordancia o asignación léxica, o la aparición de ciertos morfemas sin ser realmente marcas flexivas. En el primero de los casos, la propiedad flexiva deja de funcionar debido a la existencia en español de algunas clases gramaticales que incluyen unidades léxicas tanto invariables como variables: si tomamos como ejemplo la clase pronominal y 
determinante, encontraremos soluciones de ambos tipos en cada, algo o que frente a ninguno (ningún, ninguna, ningunos, etc.), mi (mis) o quien (quienes). Más allá de tal situación, el criterio morfológico flexivo no distingue entre categorías que admiten marcas de flexión por asignación léxica, como los sustantivos mesa/mesas, o por concordancia con dichas categorías, como el adjetivo blanco en mesa blanca/mesas blancas; ni tampoco prevé casos de la presencia de marcas morfológicas sin que se trate de marcas flexivas, como es la expresión de la temporalidad no flexiva en la palabra exembajador.

El escollo de la segunda clasificación binaria, que establece la clasificación de las categorías gramaticales a partir del criterio de la formación de series abiertas y cerradas, radica no solo en la probada pertenencia de ciertas subcategorías de la misma clase a dos series distintas — valga, como ejemplo, el caso de los cuantificadores indefinidos, de serie cerrada, y los cuantificadores numerales, de serie abierta—, sino también en la gran importancia funcional de las categorías de series cerradas (artículos, preposiciones, conjunciones, pronombres y algunos adverbios) en el manejo y uso del lenguaje. Las series cerradas son el engranaje que une las palabras de series abiertas (Bosque, 2015: 29); y tanto es así que, desde la psicolingüística evolutiva, se ha observado que niños de 2 a 3 años usan palabras de clase abierta y de clase cerrada en porcentajes muy similares para construir su discurso diario (Muñetón, Ramírez y Rodrigo, 2005: 327). Tales categorías de serie cerrada, como son los artículos y las preposiciones, forman parte del repertorio lingüístico formal y funcional obligatorio de cualquier hablante, al tiempo que las categorías de serie abierta - por ejemplo, los sustantivos o los verbos- presentan una gran variabilidad en el uso activo y pasivo de cada uno de los usuarios de la lengua.

La tercera clasificación binaria de las categorías gramaticales parte del criterio semántico para oponer clases llenas, o de asociación conceptual, y clases vacías, que carecen de asociación conceptual, pero sí poseen un significado gramatical concreto. Considerar que el hecho de poseer el significado gramatical lleva consigo la no representación de la realidad extralingüística (Cuartero Sánchez, 2002: 43) carece, sin embargo, de regularidad en la lengua española: si bien es cierto que las preposiciones como de o $a$ no se definen léxicamente, otras unidades de su clase, como para o por, sí poseen un contenido léxico claro e identificable por los hablantes. No parece, por tanto, del todo acertado recurrir al término vaciedad en la clasificación de las partes de la oración, dado que muchas categorías gramaticales sin aparente referencia conceptual guardan relaciones esenciales a nivel de la correspondencia gramatical ${ }^{2}$.

2 Esta observación, además, encaja con la perspectiva coseriana sobre las relaciones paradigmáticas en la gramática funcional, según la cual las funciones gramaticales se expresan mediante sintagmas y no mediante elementos singulares (véase Aschenberg, 2003: 59). 
Nuestro ejemplo de las preposiciones sirve, asimismo, para la crítica de la última clasificación binaria tradicional, que opone categorías gramaticales mayores y categorías gramaticales menores en función de su capacidad para introducir complementos. Qué clase formarían las preposiciones cuando analizamos sintagmas preposicionales dependería de cómo interpretamos el término - bien como complemento bien como núcleo- y abriría vías a serias inconsistencias en este aspecto.

Existe, por tanto, una clara paradoja en el tratamiento clasificatorio de las categorías gramaticales como unidades formales, puesto que no todos los elementos que forman dichas categorías cumplen fehacientemente con las propiedades que se les exige desde la gramática tradicional para pertenecer a tales categorías. Veamos qué tipo de contrariedades o problemas pueden presentar desde las divisiones morfológica, semántica y sintáctica. Como ya se ha mencionado, el criterio morfológico en la clasificación de las categorías gramaticales no toma en consideración no solo la variación que pueden presentar las unidades de la misma categoría en cuanto a poseer o no poseer flexión, sino tampoco el origen de los rasgos flexivos en diferentes categorías, la posible interpretación como rasgo flexivo de un rasgo que es, en esencia, un morfema o tal característica morfofonológica como la cliticidad, que repercute directamente en las propiedades sintácticas de algunas categorías gramaticales (valgan como ejemplo los pronombres átonos del español). Por su parte, el criterio semántico, derivado de los pensamientos aristotélico y escolástico, carece de una necesaria regularidad en la clasificación de las categorías gramaticales, cuyas propiedades en las diferentes lenguas del mundo pueden expresarse mediante categorías distintas: una «sustancia» no siempre se expresa mediante un sustantivo, como en español, sino también mediante verbos, como en algunas lenguas amerindias. En cuanto al criterio sintáctico en la clasificación de las categorías gramaticales, el hecho de que se las considere a partir de las funciones sintácticas que puedan desempeñar lo aleja, por su parte, de una perspectiva léxica y formal necesaria para tal fin: desde este criterio, serían adjetivos no solo las unidades que entendemos como tales (bonito o verde), sino también las oraciones de relativo ([el libro] que he leído) o incluso los complementos del nombre ([el libro] de Pedro), y pertenecerían a la misma categoría, en otro caso, los sintagmas nominales y las oraciones subordinadas sustantivas; algo que no es cierto (compárense Creo que llegará vs. * Creo su llegada). En realidad, el criterio sintáctico parte del principio de la homofuncionalidad y homoposicionalidad, que no asocia de forma unívoca las categorías gramaticales a una determinada función y posición sintáctica.

La relevancia del criterio sintáctico se manifiesta, sin embargo, en relación a las categorías gramaticales en el aspecto de la organización interna 
de las unidades que conforman (capítulo 3), es decir, en su posibilidad de segmentación en constituyentes (como en la cara de niño [de Pepe]) y en sintagmas (como en la cara del niño [de Pepe]) como dos unidades distintas y, por consiguiente, en su valor semántico y su función sintáctica. En los sintagmas, el aspecto esencial es el núcleo o la categoría que posee la misma distribución y naturaleza categorial que el constituyente del que forma parte (cuatro libros de aventuras=libros); es constante (no se puede suprimir, aunque tampoco pueden suprimirse todos los complementos); y determina, por tanto, el carácter endocéntrico del mismo. La legitimación, o identificación, de los complementos en español requiere, a diferencia de otras lenguas europeas, no solo el cumplimiento del criterio de la adyacencia, o posición de cercanía al núcleo, sino también la concordancia de género y número (libros caros vs. papeletas caras).

Curiosamente, ese criterio de posición sintáctica ha sido considerado poco en el análisis gramatical tradicional, aunque parece claro que tanto la posición lineal, pero sobre todo la posición estructural de una unidad, es la que indica las relaciones jerárquicas de dicha unidad con otros miembros oracionales. En dicha posición, cabe recordar, es de suma relevancia la selección semántica de un núcleo respecto de sus complementos, en tanto que determina la gramaticalidad de la estructura argumental dentro de compuestos sintácticos con funciones distintas. A propósito, Fernández Ramírez (1995) incluso define el orden de las palabras como una categoría gramatical más de una lengua.

\section{RELACIONES Y DIFERENCIAS ENTRE LAS CATEgorías GRAMATICALES}

Uno de los principales problemas en la clasificación de las categorías gramaticales es la distinción que puede establecerse entre ellas en los casos más dudosos. Empecemos con el ejemplo de los sintagmas nominales (sN) y de las oraciones sustantivas (os) (capítulo 4), dos categorías sintagmáticas con la misma función sintáctica y actuación como argumentos nominales y oracionales, respectivamente, del predicado que los selecciona. Un sN y una os se diferencian, ante todo, por su capacidad de ser seleccionados como complemento a partir de la base semántica del predicado: el verbo comprar admite un sN, pero no una os, como en compré pan/*compré que María me pidió). Existe de antemano, por lo tanto, una base semántica que permite diferenciar estas dos categorías entre sí. Ahora bien: ¿cómo debe afrontarse esta diferenciación en el caso de los verbos que pueden introducir ambos tipos de argumentos? Según el gramático, estamos ante dos opciones: la primera consiste en tratar dichos verbos como predicados diferentes con entornos de selección distintos, en los que el argumento oracional será resultado de un procedimiento metafórico, como en no es amigo de hacer favores; 
la segunda prevé tratarlos como el mismo predicado, cuyo comportamiento como seleccionador de $\mathrm{SN}$ u os es previsible a partir del significado verbal y argumental, dando lugar a asociaciones productivas, como en destinado a morir. Queda claro que el papel fundamental está en el valor denotativo de los argumentos, tanto como SN como os, y su carácter primitivo o metafórico a la vista de cuál de ellos admite el verbo. Parece, por tanto, posible predecir la selección argumental a partir de la denotación.

Siguiendo en la línea de los nombres, pasemos al establecimiento de diferencias entre dos categorías de habitual separación en la gramática tradicional: los sustantivos y los adjetivos (capítulo 5). Cabe señalar que estas dos clases de palabras se han considerado históricamente como partes del grupo de nombres, aunque se ha demostrado sobradamente que se diferencian ante todo por las funciones sintácticas que pueden desempeñar. No obstante, distintos en su valor referencial - los primeros categorizan clases de seres; los segundos describen propiedades sin clases- algunas voces en español se pueden categorizar como ambas clases. Pongamos, como ejemplo, adjetivos que denotan características físicas (ciego, cojo), morales y psicológicas (fiel, criminal), de grupos profesionales (científico, nadador) y rasgos sociales, como nacionalidades (inglés), características religiosas (católico) e ideológico (liberal), y que pueden funcionar como nombres, es decir, pasar de denotar propiedades a denotar clases. Esta posibilidad de convertir adjetivos en sustantivos es debida a factores puramente extralingüísticos, independientes de las previsiones del léxico, y explica por qué en la misma lengua - como es el español- algunas variedades admiten tal conversión y otras no. Existe, además, una restricción semántica en cuanto a la posibilidad de la conversión adjetival en nombres, que recae sobre la atribución valorativa y hace posible ser un infeliz, pero no *ser un feliz. Quizá uno de los procedimientos más comunes en la sustantivación de los adjetivos sea la elisión del núcleo de un SN con complemento del nombre adjetivo, por la conceptualización de dicho complemento como la propiedad categorizadora, como es en el caso de un coche descapotable/un descapotable. Estamos ante casos de la conversión de la cualidad en una característica denominadora; conversión que puede derivar en la pérdida factual del adjetivo base y en pervivencia única del sustantivo obtenido, como en aperitivo o motor. La tendencia opuesta - el paso del sustantivo a ser y funcionar como un adjetivo- presenta asimismo restricciones semánticas, normalmente a colores y flores, como es el caso de una rosa/color rosa/dos corbatas rosas. Causa, sin embargo, una duda gramatical importante: ¿qué son azul claro y Renault, formas invariables frente a rosa/rosas, en sintagmas como dos corbatas azul claro y coches Renault, sustantivos o adjetivos? La argumentación del autor nos sitúa ante el tratamiento de dichas unidades como sustantivos que funcionan como SN 
en relación apositiva, rechazando la idea de que sean adjetivos por el mero hecho de que no se pueden expandir (azul claro no puede expandirse a azul claramente). Dichos sustantivos poseen dos propiedades sintácticas peculiares: se adjuntan sin ninguna preposición de mediación (decimos una falda talla cuatro, no *una falda de talla cuatro), ni tampoco requieren preposición para introducir sus propios complementos. La idea fundamental en torno a esta vertiente de sustantivos como formas apositivas con aparente funcionalidad adjetival nos la resume así Ignacio Bosque (2015: 113): «las unidades sintácticas que modifican a los sustantivos no son necesariamente adjetivos por el hecho de hacerlo».

Las relaciones que establecen los adjetivos con otras categorías gramaticales los vinculan de forma particularmente estrecha a la clase adverbial (capítulo 6). Es habitual encontrar la postura que define los adverbios como la clase «peor definida en las gramáticas», en parte, por el carácter demasiado abarcador de lo que habitualmente se entiende por esta parte de la oración. No es extraño, por tanto, que se defina el adverbio como una categoría que abarca elementos «enormemente variados y heterogéneos, de las más diversas procedencias y con diferentes formas, funciones e, incluso, significaciones» (Satorre Grau, 2009: 131) y vuelve a transcender en Ignacio Bosque la idea de dejar de manejar esta categoría tan poco precisa y uniforme. Ahora bien: aunque las diferencias fundamentales entre adjetivos, como clases con flexión y con calificación de los sustantivos, y adverbios, que complementan la significación del verbo, no suponen serios altercados interpretativos de ambas clases, existen en la lengua española algunos casos dudosos que vinculan los adjetivos y adverbios de una forma muy cercana. Son casos del uso de los cuantificadores, que pueden tener forma pronominal, sustantiva, adjetiva o adverbial (Satorre Grau, 2009: 145) y que en español pueden tener valor adjetival (tanto arroz) como adverbial (trabajar tanto); y del funcionamiento de los así llamados adverbios adjetivos, o adverbios con forma de adjetivos, como en hablar claro. Estos últimos forman una subclase gramaticalmente variable que no comparte todas las funciones sintácticas con los demás adverbios. En primer lugar, no tienen el mismo grado de restricción en cuanto a la combinación verbal, dando lugar a adverbios como primero o rápido, combinables con prácticamente cualquier verbo; adverbios como firme, más restringidos por su valor léxico-semántico (al verbo andar, por ejemplo); y adverbios como cierto o fijo, restringidos prácticamente a un único verbo (aquí, a los verbos saber [algo] y mirar [algo], respectivamente). En segundo lugar, son restringidos diatópicamente (encontramos, algunas variedades del español americano la colocación cantar lindo, inexistente en el español peninsular). Y, en tercer lugar, cuentan con propiedades sintácticas específicas: mientras que algunos de ellos forman con los verbos complejos 
verbales que constituyen unidades idiomáticas en las que el adverbio no modifica al verbo (pisar firme), otros se desgranan fácilmente del verbo al que modifican (volaban, pero no muy alto). Un tercer caso problemático en el eje adjetivo-adverbio lo presentan las formas con complementos preposicionales, aceptables tanto por adjetivos como por adverbios, que no resultan sistemáticas en la transmisión del complemento adjetival en la derivación adverbial. Si bien es regular en casos como paralelo a la pared/paralelamente a la pared, no existen soluciones como responsable de sus actos/*responsablemente de sus actos o anterior a su vuelta/*anteriormente a su vuelta, y una explicación de ello radica en aceptar que casos como paralelamente a la pared deben tratarse como sintagmas preposicionales. Por supuesto, existen muchos más casos que acercan los adjetivos a los adverbios, dificultando su análisis gramatical incuestionable. Por ejemplo, la categorización en construcciones como un cocinero excelente puede ser interpretada como propiedad o como modificador de sustantivo deverbal, que da lugar a una interpretación activa de los adjetivos, propia de forma exclusiva de adjetivos valorativos por ser los únicos que predican de los individuos y las acciones que estos realizan. Además de ello, ciertos adjetivos, en lugar de calificar a los sustantivos, sitúan temporalmente la predicación del sustantivo (el actual primer ministro del Japón, donde actual se corresponde con el valor de actualmente); o modifican a sintagmas cuantificados (duró una hora escasa (escasamente)), acercándose funcional y formalmente al grupo adverbial.

Existen unas importantes relaciones de cercanía entre las dos categorías con la mayor transparencia morfológica y sintáctica para ser diferenciados entre sí en la lengua española: los sustantivos y los verbos (capítulo 7). Las relaciones de semejanza entre estas dos clases se dan a varios niveles, haciéndonos pensar que, a veces, son más similares desde el punto de vista gramatical de lo que nos parece. Así es el caso, por ejemplo, de las formas impersonales del verbo, en particular del infinitivo, que diferentes gramáticas han venido definiendo bien a favor de su carácter sustantivo por sus funciones sintácticas, bien a favor de su carácter verbal por su capacidad de establecer relaciones sintácticas verbales, como admitir un sujeto o un complemento directo. A propósito de esta forma, Bosque argumenta la posibilidad de que el infinitivo pueda funcionar tanto como verbo como nombre en contextos diferentes; existen, por lo tanto, infinitivos nominales e infinitivos verbales, que no aceptan más que dichas características debido al choque de las propiedades nominal/verbal. Los infinitivos verbales admiten sujeto (El andar María), adverbios de modo (el vivir bien), propiedades verbales (el vivir bien la gente) y adverbios temporales (el llamar ayer María); aceptan formas pasivas (ser amado), tiempos perfectivos (haber amado) y perífrasis modales y aspectuales (el tener que marcharse el profesor). Los infinitivos nominales, 
por su parte, admiten adjetivos (el buen vivir), propiedades nominales (el buen vivir de la gente) y sintagmas preposicionales con valor adverbial temporal (su llamada de ayer). No obstante, frente a esta caracterización aparentemente tan clara, existen ciertos cruces entre las propiedades verbales y nominales del infinitivo. Frente a la comentada incompatibilidad de las propiedades verbales y nominales en el mismo infinitivo, cabe resaltar el hecho de que, en los ejemplos citados — hayan sido de la modalidad nominal o verbalel infinitivo lleva el artículo, una propiedad de sN. Parece oportuna su consideración en cuanto que la presencia del artículo no siempre implica un sustantivo, sobre todo en casos con infinitivos de claro carácter verbal: valga como ejemplo la construcción el amar la naturaleza es..., donde la presencia de un objeto directo (la naturaleza) haría imposible que se tratase de un infinitivo nominal ${ }^{3}$. Además del artículo, las propiedades nominales y verbales se cruzan en casos como el continuo beber cerveza de Juan, donde coinciden cualidades nominales (el artículo, el adjetivo y el complemento nominal agentivo) con los rasgos verbales (el propio sv). Para afrontar sintácticamente dichos constructos, ofrece el gramático madrileño considerar ejemplos de este tipo como constituyentes con verbos, cuyos complementos se reinterpretan léxicamente como formas nominales. Estos casos no deben confundirse con los infinitivos nominales, que por su parte admiten formas en plurales (haberes, cantares, placeres) y no poseen relación productiva con el verbo de origen (compárense deber vs. deber/deberes) ni con contextos aparentemente neutralizantes, donde para muchos no queda patente la propiedad verbal o nominal del infinitivo, como en Un documento pendiente de firma/firmar, pero en lo que resulta es en una ambigüedad interpretativa según contexto.

Las semejanzas de introducir complementos y ser predicados comparten las categorías gramaticales de verbo y adjetivo (capítulo 8), este último, particularmente, en la forma de participio que puede tener un CD y poseer flexión. La principal polémica surge en torno a los participios pasivos que presentan cierta ambigüedad en sintagmas como edición reducida, donde para reducida existen dos posibles interpretaciones gramaticales: como verbo, si edición se considera su paciente, o como adjetivo, si reducida es una cualidad no verbal de edición. Si bien la morfología del sintagma nos recuerda a una unidad adjetival, de estas dos, la opción verbal parece más acertada sintácticamente hablando, en tanto que el sintagma analizado admite adverbios (edición recién reducida) y presenta una posición postnominal.

No menos interesantes son las cuestiones que relacionan y diferencian entre sí las diferentes categorías gramaticales tradicionalmente llamadas fun-

${ }^{3}$ Insiste Bosque (2015: 149) en que «lo que distingue al verbo del sustantivo es la capacidad de regir directamente su complemento». 
cionales, como el artículo y el pronombre (capítulo 9) y las partículas frente a los adverbios (capítulo 10). La oposición entre el artículo y el pronombre se antoja la más dificultosa debido a que ambas clases pueden compartir las funciones de actualización, determinación, referencia y sustantivación. Por su parte, la caracterización de las partículas, una «clase menor», no debe descuidarse al tener en cuenta su papel fundamental en la gramática y en la habilidad gramatical de los hablantes, a los que permite sustentar la construcción del texto (Garachana Camarero, 1999: 156). Su relación con los adverbios es de suma importancia, en tanto que no queda del todo claro cuándo hablamos de un adverbio relativo (que) y cuándo de la conjunción (que).

\section{A MODO DE CONCLUSIÓN}

La clasificación de diferentes palabras en categorías gramaticales no es idéntica en las diferentes lenguas del mundo. De la misma forma, como acabamos de ver, en una sola lengua — como es el español- tampoco hay acuerdo teórico sobre el número de clases existentes. Para algunos gramáticos, hay siete; para otros, hasta diez. ¿Cómo podemos explicar tal disparidad en el etiquetaje categorial de diferentes palabras de nuestra propia lengua?

Queda patente del trabajo de Ignacio Bosque que existe una serie de cuestiones y ambigüedades en la determinación funcional de ciertas categorías que hace difícil, si no imposible, su definitiva adscripción a una parte de la oración concreta. El acercamiento sintáctico entre las diferentes partes de la oración y la gran variabilidad de construcciones que permite crear el español en todas sus dia-variedades - la geográfica, la social, la estilística- supone un serio esfuerzo en el gramático para descifrar la naturaleza de algunas unidades léxicas y funcionales dentro de las oraciones. En este sentido, la nueva edición del manual de Ignacio Bosque es una digna respuesta a los principales escollos del análisis sintáctico y da cuenta tanto de la complejidad de la gramática española como de la ardua tarea que espera al gramático en esta labor.

\section{Bibliografía}

Aschenberg, H. (2003): «Teoría de la gramática. La concepción de Eugenio Coseriu». Odisea, 3, págs. 55-68.

Baralo, M. (2001): «El lexicón no nativo y las reglas de la gramática». Estudios de Lingüistica. Tendencias y líneas de investigación en adquisición de segundas lenguas, págs. 5-40.

Bosque, I. (2013): «Las gramáticas de la Academia: el difícil equilibrio entre el análisis y la norma». En: La lengua y la palabra. Trescientos años de la Real Academia Española. Madrid, Real Academia Española, págs. 237-244.

- (2015): Las categorías gramaticales: relaciones y diferencias. Madrid, Síntesis. 
Cervera, A. (2003): «Procedimientos morfolexicales: la categorización y la aspectualización». En Girón Alconchel, J.L. et al. (coords.): Estudios ofrecidos al profesor José Jesús de Bustos Tovar. Madrid, Editorial Complutense, págs. 61-84.

Cuartero Sánchez, J.M. (2002): “Significado léxico” y "significado gramatical” en las gramáticas del español moderno". Boletín de la Sociedad Española de Historiografía Lingüistica, 3, págs. 43-78.

Fernández Pérez, M. (1987): «La importancia de las corrientes de investigación en la configuración de la "teoría lingüística": un ejemplo con las llamadas categorías gramaticales». Verba: Anuario Galego de Filoloxia, 14, págs. 75-101.

Fernández Ramírez, S. (1995): «¿Dónde están las palabras?». Analecta Malacitana, 18.1, págs. 175-188.

Garachana Camareo, M. (1999): «Los procesos de gramaticalización». Moenia, 5, págs. 155-172.

González Calvo, J.M. (1992): «Sobre partes de la oración: artículo, pronombre, adverbio, intejección». Cauce, 14-15, págs. 87-111.

Gutiérrez Ordóñez, S. (1985): «Sobre las categorías, las clases y la transposición». Contextos, 3.5, págs. 75-111.

Mariscal Altares, S. (2001): «¿Es “a pé” equivalente a DeT+N?: Sobre el conocimiento temprano de las categorías gramaticales». Cognitiva, 13.1, págs. 35-59.

Muñetón, M.A., Ramírez, G. y Rodrigo, M.J. (2005): «Estudio longitudinal de la producción de deícticos en castellano en niños de 12 a 36 meses durante las actividades cotidianas». Anuario de Psicología, 36.3, págs. 315-337.

Piera, C. (2009): «Una idea de la palabra». En de Miguel, E. (coord.): Panorama de la lexicología. Barcelona, Ariel, págs. 25-49.

Satorre Grau, F.J. (2009): «Revisión de la categoría “adverbio" en español». Revista de Filología Española, 89.1, págs. 129-152. 